\title{
O corpo sentido e os sentidos do corpo anoréxico ${ }^{1}$
}

\section{Sensing and making sense of the anorexic body}

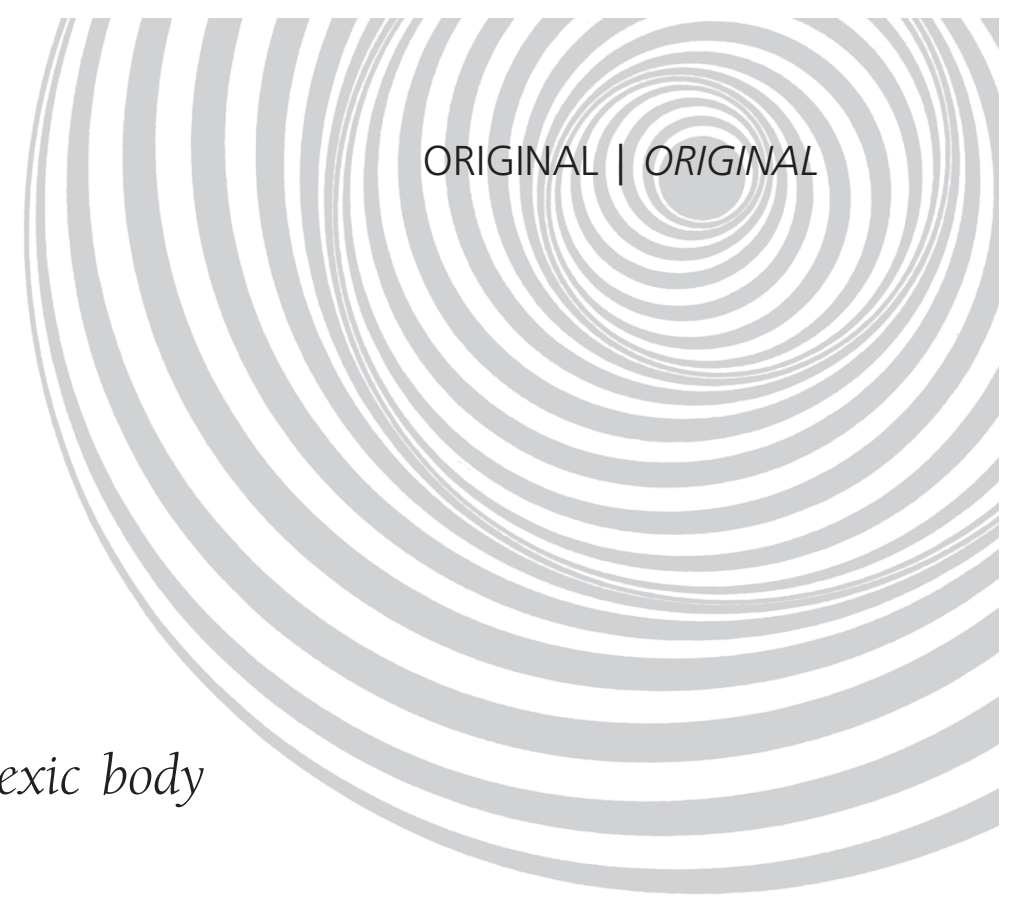

Rubia Carla Formighieri GIORDANI²

\section{RE S U M O}

\section{Objetivo}

O objetivo deste estudo é descrever a experiência corporal na anorexia nervosa e compreender os sentidos que os indivíduos anoréxicos atribuem às práticas corporais de restrição e purgação presentes nesse tipo de transtorno alimentar.

\section{Métodos}

A partir da etnografia e do método biográfico foram acompanhados oito indivíduos anoréxicos para uma descrição intensa do conteúdo das experiências de doença. Foram reconstituídas narrativas sobre a história de vida apoiadas em depoimentos autobiográficos, cartas e diários pessoais. O estudo foi realizado em Curitiba, no período de janeiro a setembro de 2003.

\section{Resultados}

A abordagem fenomenológica utilizada privilegia a experiência contada pelo indivíduo que, pela reconstituição da história de vida pretende trazer à tona o conteúdo do vivido. Nessa discussão o corpo assume uma posição central pois, além de ser o fundamento e a condição para participar do mundo social, ele aparece também como o alicerce para a experiência socialmente constituída da anorexia nervosa. Os significados atribuídos pelos indivíduos à sua experiência são o resultado de um cruzamento entre, sua história biográfica e o conhecimento significativamente apreendido por meio dela, juntamente com aquilo que foi experimentado pelo corpo em um mundo intersubjetivo. A imagem corporal distorcida na anorexia nervosa expressa um vivido relacional pela anoréxica, e as práticas corporais são a manifestação de um desejo de transformação da sua realidade.

\section{Conclusão}

Este estudo mostrou que o corpo é uma dimensão importante a ser reconhecida para a compreensão do processo de adoecer e levantou ainda questões específicas a serem estudadas sobre a gênese da anorexia nas sociedades modernas ocidentais. Revelou que a experiência corporal na anorexia comunica uma dimensão social da doença, em que os significados são sempre construídos e compartilhados com pessoas do microcosmo social do sujeito. Contar sobre essa experiência é, de certa forma, desvelar os valores culturais da sociedade.

Termos de indexação: Anorexia nervosa. Corpo. Transtornos alimentares.

\footnotetext{
1 Artigo elaborado a partir da dissertação de R.C.F. GIORDANI, intitulada "Anorexia nervosa: uma abordagem sociológica". Universidade Federal do Paraná; 2004.

2 Universidade Federal do Paraná, Departamento de Nutrição, Setor de Ciências da Saúde. Av. Prefeito Lothário Meissner, 632, Jd. Botânico, 80210-170, Curitiba, PR, Brasil.E-mail: <rubia@ufpr.br>.
} 
810 | R.C.F. GIORDANI

\section{A B S T R A C T}

\section{Objective}

This study aims at describing the physical experience felt during anorexia nervosa and understanding the sense anorexic sufferers attribute to behaviours of dietary restriction and purgation present in this kind of eating disorder.

\section{Methods}

Ethnography and the biographic method were used to follow eight anorexia sufferers to obtain a detailed description of the content of their experience with the illness. Interviews, letters and diaries were used to reconstruct the narrative of their life stories. The field work was done in Curitiba (PR) Brazil, from January to September of 2003.

\section{Results}

The phenomenological approach used in the study privileges the experience as told by the patient who uses the reconstruction of his or her life story to bring up what he or she experienced. In this discussion, the body assumes a central role because it is not only the foundation and condition for the individual to take part in the social world, but also the foundation for the socially built experience of anorexia nervosa. The sense attributed by the individual to his or her experience is the result of the combination of his or her life story and the knowledge gained by living, together with that which is experimented through the body in an intersubjective world. The distorted body image is directly related to one's life experiences and the behaviours are a manifestation of the desire of changing his or her own reality.

\section{Conclusion}

This study showed that the body is an important dimension to be recognized in order to understand the process of falling ill. It also raised specific questions that need to be studied regarding the genesis of anorexia nervosa in modern Western societies. It revealed that the bodily experience in anorexia nervosa communicates a social dimension of the disease, where the meanings are always constructed and shared with people belonging to the social microcosm of the subject. Narrating this experience is, to some extent, revealing the cultural values of a society.

Indexing terms: Body. Anorexia nervosa. Eating disorders.

\section{N T R O D U ÇÃ O}

A ciência há muito tempo tem se debruçado sobre a intervenção e o conhecimento do corpo. É um fato concreto e, ao mesmo tempo, elusivo, uma possibilidade indefinida de construções de sentido. Ultrapassada a compreensão do corpo enquanto objeto exclusivo do trabalho e do saber médico, a Psicanálise tem revelado também a dimensão inconsciente na sexualidade, assim como as Ciências Sociais têm buscado desvendar no corpo o espelho da cultura e uma materialidade atravessada pelo imaginário. Ora o corpo é percebido como natural, ora como cultural e, nesse cruzamento de possibilidades, o corpo é subjetivado a partir da gerência corporal e da sua ritualização'.

O corpo é uma realidade biopolítica, segundo Foucault ${ }^{2}$, espaço da doença e objeto de intervenção, é construído e talhado pelo discurso médico. O discurso científico na Nutrição, que opera a partir do manejo dietético a regulação corporal, fala de um corpo que se constituiu em emblema da racionalização moderna, transformou-se em objeto de poder e de saber, especialmente na ciência². Segundo Turner ${ }^{3}$, na medicina grega a dieta surgiu como uma forma de regulação do corpo. "Dieta, provém do grego 'diaita', que significa um modo de vida, ou regulação da vida, ou ainda o significado médico específico, que é de comer de acordo com as regras prescritas" (p.15). Ainda segundo Turner ${ }^{3}$, paralelamente ao aperfeiçoamento da dieta moderna, com a inclusão dos conceitos de calorias e termodinâmica, o corpo foi se tornando o foco das intervenções científicas.

Os nutricionistas, assim como outros profissionais da saúde, são treinados no olhar e no fazer a objetivar os sintomas e transcrever em sinais a subjetividade do paciente. O corpo deve ser tratado de acordo as regras canonizadas pela 
medicina moderna, e, nessa perspectiva, usando uma expressão foucaultiana, o seu tratamento inclui a regulação pela dieta. Entretanto, essa tarefa aparentemente simples de promover ou recuperar a saúde pela dieta, torna-se problemática na prática, pois há uma dificuldade em tornar possível a mudança dos hábitos alimentares e de saúde, que não se resolve somente pela comunicação ou o aprendizado mental do paciente, mas atesta para uma "resistência imposta pelo corpo, enquanto assento do hábito" ${ }^{4}$ (p.110).

A adesão ao tratamento é um problema especialmente importante no caso específico de pacientes que recusam deliberadamente, e com uma boa dose de obstinação qualquer tipo de alimento. Para o nutricionista que pretende promover uma mudança nesse itinerário auto-imposto de restrição alimentar, e que depende da mudança nos padrões da relação do indivíduo com o alimento, uma aversão radical instala um problema essencial para o êxito do tratamento.

Assim, na anorexia nervosa, situação em que o corpo é tão intensamente manipulado e a vontade de se alimentar é tão disciplinarmente controlada, surgem muitas questões para serem investigadas. Relacionam-se à forma como os indivíduos cuidam dos seus corpos e modificam seus hábitos corporais; aos sentidos que a alimentação ou, nesse caso a recusa voluntária da alimentação, pode assumir para o indivíduo. As questões dizem respeito, ainda, às causas dessa estranha e trágica doença, ou seja, em que medida a insatisfação com o corpo mantém-se atrelada à internalização de um ideal de beleza relacionado à magreza, e como essa hexis corporal torna-se padrão quase religioso a ser cumprido em sua forma simétrica.

A imersão no universo de indivíduos com anorexia nervosa implica também em uma aproximação da realidade de sofrimento e angústia, enquanto uma dimensão importante da doença. Do ponto de vista sociológico, o estudo da doença pode compreender, além do estudo das coersões que as representações sociais podem exercer sobre as práticas corporais do indivíduo, a forma com que este se relaciona com os valores culturais de sua sociedade e como ele experimenta a dimensão vivida da cultura por meio do corpo.

A anorexia nervosa é um tipo de transtorno alimentar caracterizado pela recusa deliberada do indivíduo em se alimentar, pelo medo mórbido de engordar além de uma profunda distorção na imagem corporal|5-7. O indivíduo anoréxico preocupa-se excessivamente com a alimentação e com um ganho de peso irreal, que lhe causa sofrimento subjetivo intenso. Muitos deles desenvolvem estratégias e mecanismos para perder peso e que incluem uso de laxantes e diuréticos, vômito auto-induzido e excesso de exercícios físicos. Todavia, a perda de peso na maioria das vezes não alivia sua insistência desmedida em continuar emagrecendo, tampouco sua insatisfação com a própria imagem. A incidência desse transtorno, mais comum entre adolescentes e mulheres jovens de países ocidentais ${ }^{8}$, sugere haver traços marcadamente culturais na gênese da anorexia nervosa9 Dessa forma, pela natureza e pelas características singulares desta doença, os sentidos e as práticas corporais, em seu contexto cultural de produção, marcam a intencionalidade e o fazer da presente pesquisa.

O objeto deste estudo relaciona-se à experiência socialmente constituída do fenômeno corpo na anorexia nervosa, tendo como objetivos identificar e compreender as práticas corporais engendradas no interior da experiência da doença anorexia nervosa, bem como depreender os sentidos manifestos no corpo anoréxico.

Este estudo apresenta o fenômeno corporal na anorexia e os sentidos que os atores atribuem às práticas de restrição e purgação que caracterizam a doença. O corpo, que é o fundamento e a condição para participar do mundo social, aparece também como o alicerce para a experiência socialmente constituída da doençą, ${ }^{40,11}$.

Dessa forma, este artigo toma como pressuposto que a experiência da doença está pautada no corpo enquanto dimensão vivida da cultura e que, a maneira como o indivíduo experimenta o processo do adoecimento, relaciona-se 
812 | R.C.F. GIORDANI

a uma inscrição do mundo social no corpo do indivíduo e de todo o esforço desse sujeito para intervir na sua realidade.

A abordagem fenomenológica utilizada repousa na discussão acerca do conteúdo desse vivido, que é contado pelos indivíduos anoréxicos. Trata-se de uma apreciação dos modos pelos quais os indivíduos atribuem sentidos ao conteúdo da sua experiência, e de depreender o sentido manifesto nos modos de pensar, sentir e agir que operam um contorno simbólico sobre o corpo do anoréxico e situam o indivíduo no contexto do seu dia-a-dia. Nessa perspectiva fenomenológica, interessa saber como as práticas corporais e seus sentidos são engendrados no interior da experiência da anorexia enquanto expressão de um constructo. Em outros termos, pretende-se saber do ser que se mostra e revela uma imbricação mútua entre facticidade e sentido, e da manifestação conjunta no corpo entre a intenção e o significado.

\section{MÉTOD OS}

A abordagem fenomenológica determinou a utilização de métodos descritivos, que permitiram conhecer a experiência da anorexia nervosa a partir das narrativas elaboradas pelos sujeitos que vivenciaram a doença. O método biográfico, conforme conceituado por Ferrarotti ${ }^{12}$, possibilita, a partir de sua especificidade heurística, desvelar toda a subjetividade da narrativa que, longe de ser considerado um problema, surge como um dado importante. No relato autobiográfico o sujeito que fala, interage com o outro e também se reencontra comunicando a totalidade de uma experiência em seu contexto concreto de relações sociais. A descrição da experiência da doença na primeira pessoa envolve o sujeito na elaboração de uma narrativa consistente, a partir da reflexão sobre os fatos vividos, apreendidos, dotados de significado pelo sujeito.

A biografia, longe ser um relatório de fatos e acontecimentos, exprime "a totalidade de uma experiência de vida que ali se comunica"13 (p.20) contada e encadeada por uma intencionalidade comunicativa da narrativa autobiográfica. A especificidade heurística do método biográfico reside no valor que a narrativa adquire, assim como no estatuto que se constitui de relação social (no sentido das interações estabelecidas com seus sistemas de papéis, regras etc.). Dessa forma, a representatividade e a amostragem quantitativa são desvios epistemológicos desnecessários no arcabouço teórico em que este método está ancorado.

Para a aproximação e o conhecimento da experiência corporal na anorexia nervosa, a pesquisa compreendeu material empírico coletado a partir da narrativa autobiográfica realizada em situação face-a-face, utilizando a técnica de entrevista não-estruturada e gravada. Nesse sentido, foram utilizadas oito histórias de vida de indivíduos com diagnóstico de anorexia nervosa (recuperados ou em tratamento). Compôs o material, além dos depoimentos orais gravados, diários, prontuários e entrevistas com terceiros (pais, médicos e terapeuta). Todo o material produzido foi registrado em um diário sobre pessoas e lugares, pensamentos e emoções, enfim sobre o tempo e tudo o que recheou este estar-junto pesquisador-pesquisado.

O trabalho de campo foi realizado na cidade de Curitiba, onde eram realizados os encontros com os informantes para as entrevistas. O local para as entrevistas era determinado pelos pacientes, dados o teor e a confidencialidade dos depoimentos. A duração dos depoimentos e o número de encontros variaram para cada informante, evitando-se apenas interromper o ritmo do entrevistado e aguardar que o informante solicitasse o término dos encontros.

Todas as histórias de vida foram realizadas com indivíduos do sexo feminino, pacientes do Ambulatório de Transtornos Alimentares do Hospital de Clínicas da Universidade Federal do Paraná (UFPR) no período da realização da pesquisa (de janeiro a setembro de 2003). As faixas etárias variaram sensivelmente, sendo duas adolescentes de 16 anos, cinco jovens com idade entre 18 e 23 
anos e uma mulher casada de 26 anos. A característica econômica e social também variou, sendo quatro jovens pertencentes à pequena burguesia, e as outras provenientes de famílias proletárias.

A pesquisa foi submetida e acompanhada pelo Comitê de Ética de Pesquisa em Seres Humanos do Hospital de Clínicas da UFPR e os nomes dos informantes foram substituídos, para preservar suas identidades.

\section{RESULTADOSE DISCUSSÃO}

\section{Corpo e intersubjetividade}

O corpo é substância e simulacro, facticidade e sentido, que nos situa e orienta no mundo; a partir deste, o homem ascende ao mundo. É o ancoradouro no mundo; confundindo-se com o próprio ser, é a marca do ser no mundo ${ }^{14}$. Espaço expressivo, que integra as significações vividas, é objeto no mundo, mas diferencia-se dos outros objetos, pois é corpo perceptivo e sensível. Assim, a subjetividade é tingida pelo corpo, ao mesmo tempo em que o corpo, materialidade mundana, é atravessado por uma dimensão subjetiva, é o corpo vivido. A essa realidade do corpo, Merleau-Ponty ${ }^{15}$ expõe que o "corpo é feito da mesma carne que o mundo (é um percebido), e que para mais essa carne de meu corpo é participada pelo mundo, ele a reflete, ambos se imbricam mutuamente, (o sentido a um tempo auge de subjetividade e auge de materialidade), encontram-se na relação de transgressão e encadeamento" (p.225). Tomar o corpo como fundamento da experiência implica recuperar a dimensão vivida da cultura, no âmbito da prática e seus fundamentos corporais ${ }^{16}$. O corpo é assento da prática, pois, por meio deste é que se pode ter acesso aos outros objetos, ao mesmo tempo em que já se pertence ao mundo, em que se está inserido no mundo a partir do corpo. Portanto, se é o corpo que compreende pode-se falar então de um senso prático, de um saber que está radicado no corpo, no qual primeiro o mundo é esfera da prática, para depois se tornar objeto de conhecimento $^{14}$. Alves $\&$ Rabelo 4 afirmam que:
Há, portanto, uma relação originária entre consciência e mundo - anterior a constituição mesma dos objetos - que só pode ser compreendida quando recupero a mediação do corpo. Esta relação é pré-reflexiva ou pré-objetiva: aponta para o fato de que nossa inserção (corporal) no mundo - da cultura, da convivência com os outros - antecede a atitude reflexiva que constitui esse mundo como conjunto de objetos (e a nós mesmos como sujeitos) e a cultura como o conjunto de representações acerca desses objetos (p.109).

Doravante, ao considerar a dimensão pré-reflexiva da experiência na anorexia, caberá indagar sobre a esfera vivida da cultura, que é trazida sob a forma das práticas corporais e dos sentimentos relacionados ao corpo e aos alimentos, sem, no entanto supor a existência de uma experiência pré-social, como esclarece Rabelo et al. ${ }^{16}$.

O saber radicado no corpo, e também enraizado socialmente, constitui-se em um conhecimento prático, que possibilita uma compreensão também prática do mundo, segundo a qual as capacidades corporais são mobilizadas de modo a garantir o engajamento concreto na situação, sem que haja a necessidade de se destacar da situação e refletir sobre esta para então agir. Isso transparece na fala da adolescente Sueli, quando conta que só percebeu a perda significativa de peso algum tempo após ter iniciado a dieta, e relatando uma dificuldade em se perceber magra.

Comecei a cuidar um pouco mais do meu corpo que não me satisfazia, me frustrava. Esse cuidado saiu do meu controle.

... Talvez pela mudança tão rápida, inédita e significante na minha aparência e nas minhas dimensões eu tenha perdido a noção de que já estava magra. É como se fosse a transição do inverno para o verão sem a primavera. De repente você está magra! Mas você começa a achar que não está suficientemente magra (Sueli, 16 anos). 
Essas considerações atestam para uma nova dimensão da enfermidade: o modo como o sujeito vivencia a perturbação, a dor e sua angústia proclamam uma síntese espontânea entre o corpo e a cultura, que se dá antes da representação sobre o objeto (neste caso, a doença).

O corpo vivido é marcado pela doença, suas sensações orgânicas (sinais e sintomas) e também pelo sentimento de adoecer, no sentido da dimensão vivida da cultura. É a materialidade da doença, lugar no qual se experimenta com intensidade a sensação corporal da dor provocada pela fome: o corpo frio, a queda do cabelo e a pele seca ocasionadas pela desnutrição. A angústia da próxima refeição que não será feita, a transgressão do limite último das necessidades da carne, como sensação de controle, é o ponto em que o corpo assume o sentido máximo de subjetividade.

... eu tava com medo de... estou ainda com medo de perder todos os cabelos, porque está caindo, caindo. Daí eu falei para a doutora, e ela falou que cai mesmo por causa que o corpo está sem nutriente, sem vitamina, sem proteína. Daí ela falou que cai mesmo... eu tava com muito medo disso também! (Francine, 16 anos).

Eu fico pensando o quê vai me fazer voltar a comer: esse monte de remédio que eu tomo aqui? O soro? Isso não vai me fazer voltar a comer! (Silvana, 20 anos).

Francine, que está há algum tempo com anorexia, percebe espantada as conseqüências de não comer, teme seqüelas, porém, às vezes insinua estar testando seus limites físicos. Já Silvana, que está em uma fase mais avançada da doença, permanece paralisada diante do medo da comida; aterrorizada pela possibilidade de engordar, espera que alguém prove a ela que está errada. Devolve com sofrimento em forma de pergunta aquilo que não conseguiu responder: por que não pode ir adiante? Convicta de seu itinerário purgativo gostaria que alguém a convencesse de que é necessário alimentar-se.
Para além desse caráter voluntário da privação alimentar, o quê as anoréxicas tentam explicar sobre suas experiências, diz respeito a uma resistência que é imposta pelo corpo, ou a um saber que é experimentado pelo corpo e não pelo intelecto. A prática denegatória da abstinência alimentar parece a confissão de uma vocação secreta que se realiza pelo gerenciamento do espaço corporal.

Minha única resistência ainda é comer. eu estou aqui e não quero comer mais! Como é que eu vou voltar a comer de novo? As pessoas perguntam: 'você quer um leite?', e eu tenho pavor de comer, pavor, pavor, pavor. E eu não consigo mudar esse conceito de mim. Às vezes eu tenho a impressão de que eu nunca mais vou voltar a comer, de sentar na mesa, sabe! Eu queria poder fazer isso sem essa idéia de que vai engordar (silêncio). O problema é com o corpo e com a comida (Silvana, 20 anos).

No começo foi difícil... foi difícil até que eu aceitei como as coisas são! Jantar, tomar café... almoçar, eu já almoçava, mas a janta e o café eu tive que começar a tolerar... (Dinora, 26 anos falando sobre o período que esteve internada no Hospital Psiquiátrico).

Silvana e Dinora tratam do corpo e da comida com um sentimento que passa ao largo da naturalidade: comer é sacrifício sobre-humano. Há uma elaboração equivocada sobre as rotinas fisiológicas e o corpo, como parte dissociada do sujeito, passa a ser investido de uma artificialidade. A anoréxica testa a plasticidade do seu corpo e o instrumentaliza em favor de se realizar no alcance máximo da abstinência, rompendo com as necessidades da sua carne.

Às vezes eu chego em casa fraca, mas se eu tenho que sair para andar eu vou... Se não, eu não procuro nem alimento. 0 medo de engordar é constante; eu posso até estar alegre, mas o pensamento tá ali, vinte e quatro horas por dia... como se fosse um fantasma (Diane, 19 anos). 
Para Diane, a anorexia é vivenciada como uma perturbação inabalável: é um pensamento inflexível, um fantasma tão próximo e íntimo que acabou incorporado à sua rotina. Chega a dar a impressão que aprendeu a conviver com ele quando relata com desenvoltura sobre suas recaídas em anos de tratamento.

A anoréxica retorna ao vivido para explicar a natureza de sua experiência; volta-se para o conteúdo experimentado em um movimento de reflexão ${ }^{17}$, o objetiva por intermédio da linguagem, assim o percebido se torna visível| ${ }^{14}$ : as sensações e sentimentos relacionados à comida e à abstinência alimentar são a forma da própria coisa - a doença - que é "vivida dia a dia sem que isso seja conscientizado ou verbalizado" ${ }^{18}$, exceto pela reflexão.

É o corpo perceptivo da anoréxica que se abre sobre as coisas, conhece e se reconhece no outro, pois a percepção é o modo de acesso aos objetos e ao mundo ${ }^{14}$. O conceito de percepção de Merleau-Ponty não se esgota na percepção sensorial, mas se refere a um "modo originário de ser numa totalidade enquanto vivido" 19 (p.76). Não se esgota na coisa percebida, mas se abre sobre as coisas; não está em um lugar como o objeto está, mas é uma totalidade que se abre para o horizonte repleto de perspectivas ${ }^{14}$.

Dessa forma, a percepção permite o acesso ao mundo antes mesmo da reflexão, ou seja, é pensamento de perceber, no qual o que pensa e o que é pensado estão fundidos. Essa fusão entre o que pensa e o que é pensado determina uma concepção de sujeito situado no mundo e sempre sujeito-em-relação, e, que na experiência perceptiva do mundo estão integrados. Sobre isso, Merleau-Ponty ${ }^{14}$ afirma:

A percepção é justamente este gênero de ato que não poderia tratar de colocar à parte o próprio ato e o termo sobre o qual ele versa. A percepção e o percebido têm necessariamente a mesma modalidade existencial, já que não se poderia separar da percepção a consciência que ela tem, ou antes, que ela é, de atingir a coisa mesma. Não se pode tratar de manter a certeza da percepção recusando a certeza da coisa percebida (p.500).

A percepção relaciona-se ao corpo que é sensível a tudo, e "se percebemos com o nosso corpo, o corpo é um eu natural e como que o sujeito da percepção"14 (p. 278). Perceber é fazer presente alguma coisa a partir do corpo, ascendendo à experiência no mundo, antes da reflexão. Merleau-Ponty ${ }^{14}$ fala de um conhecimento prévio à consciência, que se caracteriza pela possibilidade e não pela objetividade. O corpo não é somente fático, mas é constructo transcendental para compreender a condição de ser-no-mundo.

Ocorre, então, que, na elaboração integrada de uma experiência originária, consciência e corpo, sujeito e objeto, pensamento e pensado estão fundidos. Se todo o indivíduo é originariamente social e se está em processo de coexistência, sentindo o outro por meio do seu corpo, e também é sentido pelo outro, então a experiência corporal na anorexia nervosa está marcada pelo social. É a manifestação da teia de significações, da qual a subjetividade do sujeito anoréxico é construção a partir da coexistência e da interação social.

O sujeito encarnado é o ser-em-situação e ser-em-relação, e que, radicado em um contexto social, relaciona-se com o outro em processo de coexistência. Esse é o mundo intersubjetivo e se refere a um mundo compartilhado com os outros semelhantes, também vivenciado e interpretado por eles; é um mundo comum a todos, no qual a esfera do nós é ingenuamente pressuposta ${ }^{20}$.

Há uma tentativa por parte do próprio narrador de reconstruir a trama social em que está imerso, e a elaborar uma retórica da vida social, na qual o indivíduo não está mais solitário, mas compartilha coletivamente sua vida com seu entorno, os familiares, amigos e pessoas significativas para ele. Assim contam Silvana e Francine:

Quando meu namorado foi embora eu fiquei sozinha... Como não tinha um 
816 | R.C.F. GIORDANI

relacionamento bom com minha mãe, eu saía num dia e voltava no outro mas ela não perguntava onde eu estava (Silvana, 20 anos).

Então minha mãe ficou grávida de mim, daí ela, mãe solteira foi morar com a minha tia, daí com a minha tia não deu certo e ela foi morar com a minha vó e depois voltou com a minha tia de novo em Maringá. Daí quando eu tinha um aninho ela conheceu um homem que disse que ia me dar tudo e que seria como um pai pra mim, o que eu precisasse ele estaria pronto. Minha mãe acreditou e acabou casando com ele e aí nasceu meu primeiro irmão por parte de mãe... E começou... não queria mais que eu ficasse assim... comunicando com a minha mãe. Queria que eu ficasse no canto, quieta. Ele falava que eu era uma criança irritante... e eu lembro de tudo (Francine, 16 anos).

Silvana, seu amor perdido e a mãe. Francine, a mãe e seu padrasto perverso. Assim, o sujeito é ser-no-mundo, sujeito encarnado com sua consciência relacionada ao mundo. A vivência é sempre percebida em relação ao outro e, informar sobre o processo de adoecer, é também uma reorganização das experiências anteriores mais significativas, em função do estoque de conhecimento do indivíduo ${ }^{20}$. Para Schutz ${ }^{20}$, esse estoque de conhecimento à mão funciona como "um código de interpretações de suas experiências passadas e presentes" (p.74), e lhe permite avaliar situações, bem como antecipar ou planejar seu futuro. Junto a essa bagagem acumulada ao longo da história biográfica, o sujeito dá contornos e imprime significados à sua dor ${ }^{20}$.

O compartilhamento das emoções e do afeto no espaço da sociabilidade e a vivência comum é que dão o sentido da vida individual e social $^{18}$. A anoréxica fala da sua experiência utilizando a descrição dos modos de convivência familiar, de pessoas significativas e de suas atividades diárias. Conta sobre o cotidiano e sobre aquilo que costumeiramente não é objeto de reflexão, mas apenas realizado e imbuído de um sentimento de convivência ${ }^{18}$. Kely relaciona a saída de casa como a busca de uma identidade diferente da sua referência familiar, esta representada, nas suas palavras, pela "passividade", e, como se a anorexia fosse uma busca de si, relata:

... foi bom também o fato de ter saído de casa, tudo o que eu aprendi... a ser mais ativa nas coisas que eu faço. A gente tem uma educação muito passiva. Talvez a questão, minha mãe, ela é muito neurótica, exigente, meticulosa, assim, ela é muito detalhista. O fogão tem que estar impecável, o vidro estar impecável, e de repente eu queria estar impecável comigo mesmo, não só minha aparência (Kely, 23 anos).

Nessa fuga de uma estrutura familiar aparentemente rígida, Kely reflete sobre sua doença e relação com a família. Sair de casa, no contexto da doença representou para ela a cura da anorexia: em um movimento de se desprender da família e de conquistar algo diferente para si, se descobriu capaz de empreender e realizar.

\section{O Projeto da anoréxica}

As narrativas produzidas pelas anoréxicas deflagram uma quase teatralidade na convivência social, a partir da descrição minuciosa das performances bem sucedidas para controlar as impressões das pessoas ao seu redor ${ }^{21}$. Todavia, nesse espetáculo da vida cotidiana, a encenação anoréxica engendra uma tensão entre seu desejo de emagrecer cada vez mais e as expectativas dos outros indivíduos acerca do seu corpo.

Eu me sentia bem, super feliz. Cada dia que eu colocava a calça jeans e que ficava larga, eu: 'Ahhh que bom!' Isso me motivava mais, me dava mais força pra conseguir emagrecer mais. Essa época eu perdi trinta quilos! (Queila, 22 anos). 
Queila revela que vive intensamente a partir das expectativas dos outros sobre ela. Sempre teve sobrepeso e fazer dieta, além da motivação pessoal, é agora também a sua profissão. Com sofrimento, ela confessa seu constrangimento diante da turma da faculdade, em que freqüenta o curso de Nutrição. Sente-se cobrada por não conseguir se controlar diante da comida: tempos atrás estava caquética e agora exibe outra silhueta em virtude de uma compulsão alimentar que está enfrentando. Os tempos de anorexia recordados por Queila são bem vistos, pois Ihe parece que tinha o controle sobre as coisas e a vida. Conta como ser magra Ihe possibilitava uma vida social satisfatória, como se a magreza fosse uma condição para a felicidade.

Todavia, esse emagrecimento deliberado sem ponto de chegada para a anoréxica, tem limites bem claros do ponto de vista biológico e social, afinal a prática anoréxica pode ser a expressão máxima da relação patológica que um indivíduo pode ter com o seu corpo e com a comida.

Decorre que, dessa tensão e incompatibilidade entre a obstinação resoluta em perder peso e a demanda social do papel de menina normal a que ela tem de dar expressão, deriva sua entrega secreta à abstinência alimentar, ao exercício físico realizado até a exaustão e a outras práticas corporais purgativas.

Às vezes que eu ficava com raiva em casa, brava com alguém, ia pro meu quarto e às vezes fazia abdominal sem contar... (Ana Maria, 19 anos).

Chegou num ponto que eu tava tão desesperada pra perder peso que eu colocava detergente num copo com água, enchia de água e tomava sabe... como se aquilo fosse "emagrecedor" (Diane, 19 anos).

A busca incansável pela magreza é a realização de um projeto e de significados no corpo, que requer um investimento concreto do indivíduo para consumá-lo. Entretanto, se todo projetar repousa em ensaiar dramaticamente o futuro, envolve também as possibilidades atuais para a realização do projeto e, o mais importante, sua definição não é mero resultado de operações mentais. Trata-se de um movimento em que o sujeito se lança ao futuro a partir do seu contexto social, para a realização de algo que é empreendido à luz de sua situação biográfica e do seu estoque de conhecimento ${ }^{20}$.

O projeto a ser realizado pela anoréxica, não é simples escolha racional, mas é o sentido que engendra as práticas corporais e mobiliza suas capacidades corporais em um movimento de reorganização do espaço do corpo. O corpo vivido não é apenas simulacro de intervenções, mas se confunde com o próprio ser e, nesse sentido há uma fusão na qual curiosamente o ator (anoréxico) e o personagem (a menina normal) tornam-se assumidamente uma só subjetividade. Não haverá mais então um indivíduo empenhado em concretizar seus planos e que precisa desenvolver estratégias que garantam sua realização, o que inclui manter controle sobre a impressão que os outros tem dele. É que, após o desencadeamento do processo mórbido mantido em segredo por algum tempo e normalizado pelo discurso, o ator torna-se um cínico.

Meus pais sabiam, tentavam conversar comigo, mas era numa hora que eu já tava querendo descontar; então acabava sendo... rude com eles. Eles ficavam nervosos, saíam e ficavam conversando entre eles e eu fazendo exercícios!!! Sabia que eles sabiam, sabia que eles estavam preocupados comigo, mas eu precisava descontar de algum jeito... eu não queria ficar obesa de novo, então pegava exercício mesmo e fazia! (Ana Maria, 19 anos).

Goffman ${ }^{21}$ usa o termo cínico quando se refere à crença no papel que o próprio indivíduo representa e, neste caso, o ator não se interessaria se o público acreditasse ou não em sua performance. Essa metáfora do teatro parece apropriada para descrever a encenação produzida por Ana 
818 | R.C.F. GIORDANI

Maria, ao ironizar a preocupação dos pais e sair de cena. Não somente desacreditada de seu papel de boa menina, Ana Maria pouco se importava com a opinião dos seus expectadores.

Para a anoréxica, representar a normalidade não é mais prioridade e sustentar a impressão de que tudo está sob controle não a envolve totalmente. Em muitos depoimentos isso fica demonstrado quando a anoréxica, ao contar sua história de vida e sobre o início da anorexia, refere-se a uma quase fatalidade que teve início após uma decisão deliberada, e que Bidaud ${ }^{22}$, apropriadamente, chamou de efeito cínico de uma vocação.

Naquele momento eu tinha uma prima que começou a trabalhar no mercado e ela começou consideravelmente a perder peso. Como se ela estivesse me desafiando e dizendo 'eu estou mais magra que você!'; daí eu comecei a ficar sem comer. Eu passei a evitar tudo quanto é tipo de alimentação (Diana, 19 anos).

Diana fala da anorexia como se a doença fosse inevitável em sua vida; uma espécie de talento natural cultivado durante anos. O episódio contado sobre a prima e a rivalidade entre elas, por vezes estimulada pela família, apenas despertara essa inclinação.

Há um momento em que o sujeito assume integralmente a parte do seu self, realização dramática do seu devaneio, que era ocultado até então para a platéia. Aquela intencionalidade que secretamente instrumentalizava seu corpo, e lentamente começava a se mostrar: a anorexia. Essa fusão entre o ator que mobiliza o seu corpo e o seu personagem que aparece a partir do seu corpo, é a realização do projeto a partir do corpo no corpo; é a construção do corpo desprovido das necessidades orgânicas e da marca do social na realização do corpo descarnado. Há uma imbricação mútua entre o sujeito que enuncia a partir do corpo e o enunciado que é dado no corpo, de tal forma que, a maneira de vivenciar a redução do peso é perturbadora e assume contornos patológicos: a anoréxica ignora os riscos implicados nas suas práticas.
Para Queila, que lamenta não ter se mantido na magreza extrema, a volta à obesidade Ihe parece um pesadelo. Ela que tão bem conhece o transtorno, pois é nutricionista, não entende como naquele período em que se sentia tão feliz, poderia estar com anorexia. As fotos mostradas com orgulho e os olhos cheios de lágrima durante a entrevista, evocam em Queila o desejo de voltar a fazer tudo de novo.

Já o discurso de Ana Maria é marcado por sentimentos ambíguos e confusos, em relação ao período em que esteve anoréxica. Levantando a voz fala que às vezes se revoltava muito com o controle dos pais e dos médicos sobre sua saúde, não entendia porque sua magreza incomodava tanto os outros; ou ainda, que estava gorda e se sentia constantemente insatisfeita com o peso.

Ao contar a experiência da doença, as anoréxicas tentam buscar um sentido novo para o vivido; o cotidiano é laborado sob outro prisma e o efêmero passa a ser investido de um significado histórico. Nas palavras de Schutz: "do ponto de vista do ator na vida diária, é impossível a nitidez total dos elementos envolvidos no processo da escolha, ou seja, é impossível uma ação 'perfeitamente' racional"20 (p.147). Somente em retrospectiva o ator pode vislumbrar o significado do qual fora dotado seu sistema de planos, pois quando está imerso na ação cotidiana ele apenas vive. Além do mais, o projeto diz respeito a um sujeito encarnado e enraizado em um cenário social específico, no qual a situação biográfica está constantemente sendo renovada. Por exemplo, Francine retrata hoje sua anorexia como o resultado de uma vida familiar atribulada, conta sobre seu cotidiano e os problemas que enfrenta em sua rotina. Não consegue vislumbrar uma saída para seu estado atual, a não ser que haja uma reviravolta na sua vida pessoal.

Qual o sentido para esse empreendimento tão arriscado que constitui a anorexia nervosa? Para o sujeito que o protagoniza, os significados iniciais parecem se perder durante o caminho e, dessa forma, o projeto vai sendo transformado. 
Para Francine, o sentido para tudo o que tem vivido atravessa diferentes níveis de interpretação. Às vezes decorre de uma história de vida marcada por fatos conturbados e dificuldades. Outras vezes parece achar que tudo é efeito descontrolado de uma espécie de capricho impensado. Nesse ponto pode-se retomar Schutz ${ }^{20}$, quando relativiza a racionalidade da ação para a realização do projeto e afirma que o estoque de conhecimento é sempre reatualizado, dando constantemente ao indivíduo novos horizontes de análises e escolhas.

Por outro lado, o manejo corporal e a abstinência alimentar, investimentos práticos do indivíduo e que constituem a marca sintomática da anorexia nervosa, revelam uma maneira própria do ser que se mostra no mundo. Os sintomas aqui são metáforas que comunicam para além da tragédia pessoal que pode ser a anorexia nervosa, um conhecimento radicado no corpo, fruto do vivido que é inscrito no corpo e que se expressa como um modo particular de ser/estar no mundo: o esquema corporal.

É pelo corpo que se abre a possibilidade de ter acesso ao mundo e aos objetos e se experimenta o "acordo entre aquilo que visamos e aquilo que nos é dado, entre a intenção e a efetuação" 14 (p.200). Ao projetar, o indivíduo tenta reorientar tanto a situação quanto as suas capacidades corporais. A inscrição do social que tem o assento no corpo é um tipo de conhecimento prático, que reorienta e mobiliza o indivíduo para a realização do seu projeto. Entende-se, ao final, que a anorexia nervosa é uma forma de transcender essa situação, ou seja, o indivíduo, em uma tentativa de reelaborar seu esquema corporal, dilata e refaz suas capacidades corporais para transformar sua maneira de se colocar no mundo. É o ser, em, situação que explica sua doença a partir das relações concretas, em que, em um retrocruzamento de subjetividades, emerge o sentido da anorexia.

Cada vez que o sujeito faz falar o que estava adormecido no imediato da afetação, renova e reatualiza o conteúdo da sua experiência. Trazer à tona o não-dito-aquilo que emerge do contato com o mundo e que ficou marcado na carne - reinventando um significado pela comunicação com o mundo, implica em um reconhecimento de que não há um sentido inexorável para as coisas, mas, ao contrário, é a multiplicidade das situações que dá contorno aos significados.

É nesses termos que a experiência corporal na anorexia assume um estatuto formulador de sentido; o corpo tem a marca daquilo que é da ordem do social, mas também é o lugar no qual as impressões fugazes, a dor e as emoções perturbadoras emergem, solicitando ao sujeito novas reconstruções de sentido, diferentes das habituais e que possam dar a ele sentido de existência face à doença.

Ao tomar o corpo como espaço da doença amplo de significados, certamente, se atribui a este a essência de ser uma metáfora, porquanto transporta sentido. Todavia, o corpo não é tão somente simulacro, mas para, além disso, é a maneira pela qual se ascende ao mundo; ele próprio engendra sentido a partir da sua relação originária com o mundo social. O conteúdo da experiência anoréxica revela-se, ao mesmo tempo, como facticidade e também como sentido reconstruído.

Ao falar sobre a metáfora, Maffesoli18 afirma que "... sem deixar de permanecer enraizada a fundo na concretude da vida corrente", a metáfora "... não indica, de maneira unívoca, qual é o sentido das coisas, mas pode ajudar a perceber suas significações" (p.148). Sob esse aspecto, o corpo anoréxico, mais do que metáfora, ele próprio incita a produção de sentido, que, de acordo com Bezerra, ${ }^{23}$ "... não reside nem em um sentido já presente (embora travestido ou disfarçado) nem em alguma forma de proto-sentido (embutido e interpretável), mas no efeito metafórico, ou seja, no impulso à produção de sentido que ela (metáfora) engendra...". Ou seja, é no movimento que confronta o vivido com o atual e o se lançar a um futuro, que emergem os sentidos dos modos de pensar, sentir e agir, que mantêm um recorte sobre o corpo e situam o indivíduo anoréxico no contexto do seu dia-a-dia. 
$820 \mid$ R.C.F. GIORDANI

Em referência a Merleau-Ponty ${ }^{24}$, é como se, a partir dos sintomas da anorexia, enquanto forma de linguagem, se pudesse em vez de puramente copiar o pensamento - marcas do vivido - se deixar desfazer e refazer por ele. O corpo anoréxico "traz seu sentido, como o rastro de um passo significa o movimento e o esforço de um corpo" (p.45)

\section{O N CLUS Ã O}

A partir das narrativas autobiográficas de mulheres anoréxicas, se pode entender como elas compreendem e se envolvem ativamente em situações concretas, e, como o processo da enfermidade é sentido e compartilhado com outras pessoas significativas.

As práticas corporais na anorexia refletem uma dinâmica específica: a realidade corporal adquire o status de norte orientador para a existência do sujeito anoréxico e passa a marcar permanentemente a identidade do sujeito no mundo social. A figura do corpo é a problemática central sobre a qual se debruça inteiramente a anoréxica.

O corpo que protagoniza essa história, por vezes, é instrumento, outras tantas é o sentido que move o sujeito. As falas comunicam a força do corpo, de uma intencionalidade que opera a partir do corpo e por meio deste. O corpo é o ancoradouro do homem no mundo, lugar em que as marcas do social - o retrato do seu entorno, do microcosmo social - são inscritas.

Os significados atribuídos pelos indivíduos à sua experiência são resultado de um cruzamento entre, sua história biográfica e o conhecimento apreendido por meio desse, juntamente com aquilo que foi experimentado pelo corpo em um mundo intersubjetivo. É na troca relacional e social que emerge o sentido que lança o indivíduo para a renovação do seu hábito corporal e as práticas corporais são a manifestação desse desejo de transformação da realidade.
Admitir que não existe um sentido único e irredutível para as coisas, bem como acolher a idéia de que os meios e os fins não são fases separadas do processo de agir, implica recuperar uma dimensão da ação em que consciência e corpo se imbricam mutuamente e a cultura é vivida a partir de um aprendizado corporal. No movimento da ação, as intenções futuras do indivíduo são tonalizadas pelo conhecimento apreendido por seu corpo, e ao mesmo tempo se entrelaçam pela história biográfica e pelas circunstâncias em que o indivíduo se encontra. No início, o indivíduo não conhece claramente seu projeto, mas diante das possibilidades que se apresentam a ele, o seu projeto vai sendo delineado ou até mesmo transformado 4 .

Como se fosse algo fora do seu controle, as anoréxicas afirmam que não conseguem comer e que o medo de engordar é maior do que a sua fome. Secretamente e anonimamente elas não negaram que sentem vontade de comer, mas apenas confessaram o seu domínio sobre este desejo e a sensação de empoderamento nesta convicção. Dilaceram-se nessa tentação, o pensamento no alimento é constante e é interpretado como se fosse uma secreção de pensamento que a qualquer momento pode se transformar num ato ${ }^{22}$. Nessa constante que as atormenta, pensam ser melhor negar-lhe a possibilidade de se concretizar e daí nasce a sólida convicção de recusar a comida.

A compreensão sobre a experiência corporal na anorexia nervosa sugere que há um sentido engendrado no interior desse fenômeno, que comunica não somente um conteúdo experimentado solitariamente pelo indivíduo, mas revela também uma dimensão comunal da experiência. Contar sobre essa experiência é, de certa forma, desvelar o microcosmo social desse ator, como também, comunicar os valores culturais de sua sociedade.

\section{REFERÊ NCIAS}

1. Goés F, Villaça N. Em nome do corpo. Rio de Janeiro: Rocco; 1998. 
2. Foucault M. Microfísica do poder. Rio de Janeiro: Graal; 1996.

3. Turner BS. El cuerpo y la sociedad, exploraciones en teoria social. México: Fondo de Cultura Económica; 1984.

4. Alves PC, Rabelo M. Repensando os estudos sobre representações e práticas em saúde/doença. In: Alves PC, Rabelo MC, organizadores. Antropologia da saúde. Rio de Janeiro: Relume-Dumará; 1998.

5. Cordás TA, Claudino AM. Transtornos alimentares: fundamentos históricos. Rev Bras Psiquiatr. 2002; 24(Supl 3):3-6. doi: 10.1590/S1516-44462002 000700002.

6. Giordani RCF. A auto-imagem corporal na anorexia nervosa: uma abordagem sociológica. Psicol Soc. 2006; 18(2):81-8. doi: 10.1590/S0102-71822006 000200011.

7. American Psychiatric Association. Diagnostic and statistical manual of mental disorders DSM-IV. Washington (DC): APA; 1994.

8. Dunker KLL, Philippi ST. Hábitos e comportamentos alimentares de adolescentes com sintomas de anorexia nervosa. Rev Nutr. 2003; 16(1):51-60. doi: 10.1590/S1415-52732003000100006.

9. Morgan CM, Vecchiatti IR, Negrão AB. Etiologia dos transtornos alimentares: aspectos biológicos, psicológicos e sócio-culturais. Rev Bras Psiquiatr. 2002; 24(Sup 3):18-23. doi: 10.1590/S1516-4446 2002000700005.

10. Alves PC. A experiência da enfermidade: considerações teóricas. Cad Saúde Pública. 1993; 9(3):268-9. doi: 10.1590/S0102-311X19930003 00014.

11. Giordani RCF. Notas etnográficas sobre a anorexia nervosa. In: Rasia JM, Giordani RCF. Olhares e questões sobre a saúde, a doença e a morte. Curitiba: UFPR; 2007.
12. Ferraroti F. Sobre a autonomia do método biográfico. In: Nóvoa A, Finger M, organizadores. O Método (auto) biográfico e a formação. Lisboa: Ministério da Saúde; 1988.

13. Bueno BO. O método autobiográfico e os estudos com histórias de vida de professores. Educ Pesq. 2002; 28(1):11-30. doi: 10.1590/S1517-9702200 2000100002.

14. Merleau-Ponty M. Fenomenologia da percepção. São Paulo: Martins Fontes; 1999.

15. Merleau-Ponty M. O visível e o invisível. São Paulo: Perspectiva; 2000.

16. Rabelo MC, Alves PC, Souza I. Experiência de doença e narrativa. Rio de Janeiro: Fiocruz; 1999.

17. Teixeira CC. Em busca da experiência mundana e seus significados. Rio de Janeiro: Relume-Dumará; 2000.

18. Maffesoli M. Elogio da razão sensível. Rio de Janeiro: Vozes; 1998.

19. Maciel SM. Corpo invisível. Porto Alegre: EDIPUCRS; 1997.

20. Schutz A. Fenomenologia e relações sociais. Rio de Janeiro: Zahar; 1979.

21. Goffman E. A representação do eu na vida cotidiana. Petrópolis: Vozes; 1998.

22. Bidaud E. Anorexia mental, ascese, mística. Rio de Janeiro: Cia de Freud; 1998.

23. Bezerra Junior B. O lugar do corpo na experiência do sentido: uma perspectiva pragmática In: Bezerra Junior B, Plastino CA, organizadores. Corpo, afeto, linguagem: a questão do sentido hoje. Rio de Janeiro: Marca d’Água; 2001.

24. Merleau-Ponty M. Signos. São Paulo: Martins Fontes; 1991.

Recebido em: 11/12/2007

Versão final reapresentada em: 26/1/2009

Aprovado em: 14/5/2009 